\title{
Alerts for policy makers extracted from papers published during 2013 in volume 5 of Food Security
}

\author{
Richard Strange
}

Published online: 15 January 2014

(C) Springer Science+Business Media Dordrecht and International Society for Plant Pathology 2014

This item very briefly summarizes papers published in volume 5 for the year 2013 of Food Security, drawing attention to current and future critical issues in food and nutrition insecurity and measures that could be adopted to alleviate them. It is hoped that Policy Makers concerned with food security will note them and that they will inspire early action. (Numbers after each entry refer to relevant pages in Volume 5 of the journal).

\section{The physical environment}

1. Water allocation in Afghanistan: Frank Ward and associates demonstrate that, in times of water scarcity, proportional sharing of water resources obtained from canals, branching out from a river, rather than favouring farms which, for example, are upstream, is the best option for overall farm income and food security (pp. 35-53).

2. Adapting maize production to climate change in subSaharan Africa: Jill Cairns and associates advocate screening maize for drought resistance under high temperatures as tolerance to the combination of both stressors is genetically distinct from either separately and tolerance to one or the other does not give tolerance to the combination of both (pp. 345-360).

3. Postharvest agriculture in changing climates: Tanya Stathers and associates suggest that the predicted conditions of higher temperatures and humidity in Africa may lead to greater contamination of stored grain by mycotoxins and increased infestation by insects (pp. 361-392).

4. Spatial-temporal changes of cropland and climate potential in Northern China from 1990 to 2010: Qin Yuanwei

R. Strange $(\bowtie)$

Birkbeck College, University of London, London, UK

e-mail: r.strange@sbc.bbk.ac.uk and associates describe the spatial-temporal changes of cropland and productivity, which have taken place in a large area of northern China, but show that the average precipitation has decreased over the 2 decades from 422 to $258 \mathrm{~mm}$ per annum and has become more variable (pp. 499-512).

The biological environment: productivity and consumption

1. Crops that feed the World: Two crops are reviewed in this series: oats are reviewed by Athole Marshall and associates (pp.13-33) and wheat by Bekele Shiferaw and associates (pp. 291-317)

2. Maintaining rust resistance in wheat: Marcia Chaves and associates point out the fundamental role played by wheat in satisfying the calorie and protein requirements of much of the world's population and demonstrate the threat to wheat production by three rust diseases. In particular they stress the lack of effective resistance genes to the variants of stem rust, known collectively as $\mathrm{Ug} 99$.

3. Control of a disease complex of wheat: To spray or not to spray is often a difficult question to answer when attempting to control plant diseases. Kawsar Salam and associates were able to answer this question in the affirmative in relation to a disease complex of wheat caused by two fungi, Pyrenphora tritici-repentis and Stagonospora nodorum, by conducting a meta-analysis on large data sets as the increase in yield as a result of fungicide treatment was $297 \mathrm{Kg}$. ha ${ }^{-1}$ (pp. 319-325).

4. Adoption of the system of rice intensification (SRI): Kazushi Takahashi investigated the reasons for the poor uptake of the System of Rice Intensification (SRI) in a 
small and poor area of South Sulawesi, Indonesia. Poor adoption of the system was ascribed to lack of control of irrigation, for which timing is critical and which requires co-operation among farmers, and the extra labour involved (pp. 513-524).

5. Infestation of stored maize by insect pests in Tanzania: Rose Mboya showed that most stored maize (93\%) from 130 subsistence farm households in the Rungwe district of Tanzania was infested by weevils, moths or both with an average number of insects per $\mathrm{Kg}$ of grain of over 1,500 after storage for 5 months. She recommends storage of properly dried maize in air-tight bags and development of maize lines resistant to these pests (pp. 525-531).

6. Development of prawn farming with fish and rice in Bangladesh: NesarAhmed and Mark Flaherty point out that the southeast of Bangladesh has appropriate resources and favourable agroclimatic conditions for the culture of prawns, although this is currently mainly confined to the southwest of the country. They suggest that farming prawns with fish and rice in the southeast has considerable potential for increasing the food security of farming households and, owing to the value of prawns on the international market, for boosting the economy of the country as a whole (637-649).

7. The prospects of hybrid rice in India: The Indian government is seeking to improve yields by expanding the area of rice planted with hybrids to $25 \%$. This is unlikely to be reached, according to David Spielman and associates, owing to the difficulty in producing high quality hybrid seed with a sufficiently attractive yield increase (pp. 651-665).

8. An integrated agro-ecosystem and livelihood systems approach for the poor and vulnerable in dry areas: Maarten van Ginkel and associates point out that the efforts to improve the livelihoods of 400 million people, who live in the developing world and are dependent on dryland agriculture, have either not been successful or are now facing a declining rate of impact. They suggest that this has been due to piecemeal attention to individual components of the farming systems and that new more holistic approaches to research and development are needed (pp. 751-767).

9. Maximising yield benefits from dual-purpose cowpea: Ernest Dube and Morris Fanadzo call attention to the dual use of cowpea on the African continent, the leaves being used as a vegetable as well as the grain from the same plant. Clearly, a balance must be struck between harvesting these two different parts of the plant in order to maximise the total yield (pp. 769-779).

10. How sweet potato varieties are distributed in Uganda: actors, constraints and opportunities: Richard Gibson describes how sweet potato vines, the means of propagation, are distributed in Uganda, mainly by private multipliers, and suggests improvements to the system. In particular, he advocates greater use of private multipliers by the National Sweet Potato programme in order to disseminate new varieties more widely and more quickly. These include the orange-fleshed varieties that are rich in beta-carotene and can therefore combat vitamin A deficiency (pp. 781-791).

11. The adoption of sustainable practices for pummelo farming in Thailand: Yuichiro Amekawa describes how two communities of Thai farmers of pummelo are balancing the twin imperatives of sustainability and maintenance of livelihoods. One of these, located in the highlands, sold to local and domestic markets and employed low-cost-lowreturn procedures while the other, located in the lowlands, whose sales also included the export market employed high-cost-high-return procedures (pp. 793-805).

12. Fisheries and food security in Timor-Leste: In order to tackle the chronic malnutrition of Timor-Leste, Enrique Población, recommends development of the fishing industry and promotion of fish consumption. This industry has been under developed owing to local taboos (pp. 807-816).

13. Analysis of the status of entomophagy in Botswana: Motshwari Obopile and Tapiwa Seeletso suggest that a diet that includes direct consumption of insects, or livestock that has been fed on insects, could ameliorate the problem of malnourishment on the African continent. However, they report a decline in insect consumption (entomophagy) in Botswana, the only insect widely consumed being the mopane worm. In order to help reverse this, they identified 26 species of insects (beside the mopane worm) that had been eaten by Batswana in the past and describe methods of collection, cooking and storage (pp. 817-824).

\section{The socio-political and economic environment}

\section{Governance}

1. Self-sufficiency policy in the Senegal River valley: Mandiaye Diagne and associates identified intensification of rice growing, requiring the services of extension workers as well as organizational and institutional improvements, as key factors for boosting productivity (pp. 55-68).

2. Shrinking of fertile cropland in China: Wenjiao Shi and associates document the danger to grain production of encroaching urbanization on fertile land in the HuangHuai-Hai plain of China and call for optimization of land resources to ensure soil fertility and maximization of nitrogen and water use (pp. 69-82). 
3. Livelihood strategies and soil management in Ethiopia: Ali Oumer and associates show that better off households involved in a potato-based agriculture were more likely to undertake improved soil management practices than others who practised alternative and less remunerative livelihood strategies (pp. 143-156).

4. Policies for food security in Asia: Kym Anderson and associates state that Asia is home to the majority of the world's poor and that $60 \%$ of their budget is spent on food, making them vulnerable to price hikes. They advocate using domestic policies to deal with these shortterm fluctuations but boosting the growth rates of agricultural productivity to deal with long-term concerns (pp.195-215).

5. Policies for food security in South Africa: Scott Drimie and Milla McLachlan argue that food systems are complex and must be addressed by a systemic approach which will require disciplinary and interdisciplinary research involving health, agricultural and social sciences as well as engineering (pp. 217-226). In an accompanying paper, Greta Geldenhuys and associates suggest that gamebirds could provide a sustainable food source in Southern Africa providing that stringent qualityassurance procedures were implemented (pp. 235-249).

6. Mussel and oyster culture in Saldanha Bay, South Africa: David Olivier and associates demonstrate the enormous potential for growth of this industry $-10-28$ fold - and consequent employment opportunities because of the favourable ecology of Saldanha Bay for mussel and oyster culture. Unfortunately, this is not currently realised on account of formidable bureaucratic obstacles, which should be susceptible to enlightened legislation, in the areas of high lease fees for water, lack of medium- and long-term tenure and under-cutting by subsidized imports from abroad (pp. 251-267)

7. Effects of urbanization on arable land requirements in China: Guilin Li and associates suggest three approaches to relieving the pressure on arable land caused by urbanization and increased meat consumption in China: consumption patterns should be changed to more plantbased food, import of land-intensive food should be increased and there should be investment in agricultural research and development (pp. 415-416).

8. Welfare effects of alternative targeted food subsidy programmes in Iran. Abdoulkarim Esmaeili and coworkers show that non-needy urban and rural groups in Iran receive $56 \%$ and $65 \%$, respectively, of the benefit from the food subsidy programme there. They suggest replacing the existing programme with one aimed at foods consumed heavily in low-income households. However, the authors report that the Iranian government is considering the elimination of all subsidies, including those for food (pp. 451-456).
9. Perspectives on the causes of food riots in Africa: Lauren Sneyd and associates analysed 14 African countries where food riots occurred and showed that internationally, these were seen as poverty, hunger and global profiteering, whereas local perceptions were of citizen dissatisfaction and local merchant profiteering (pp. 485-497).

10. Priority questions for the UK food system: John Ingram and co-authors found, in answers to questions in a large survey, that food affordability, nutrition and food safety were the issues of principal concern (pp.617-636).

Food safety

1. Food safety and the dose-response curve: Edward Calabrese calls attention to the fact that current regulatory procedures do not pay sufficient attention to hormetic dose-responses whereby concentrations of chemical compounds below those recognised as the threshold of the major effect may have positive or negative effects. These may be desirable or undesirable and clearly have implications for food safety (pp. 95-102).

2. Exposure of meat consumers in Turkey to bacterial hazards: Irem Omurtag and associates show that the risk of bacterial hazard from meat in Turkey is related to demographic/socio-economic factors and dietary habits, including insufficient cooking (pp. 103-115) and in an accompanying paper follow this up with specific reference to Campylobacter spp. (pp. 117-127).

3. Food chemistry, chemophobia and the use of antibiotics: Gordon Gribble defines chemophobia as the exaggerated fear of anything 'chemical', an attitude that is widespread in the Western World and Asia. But everything, including all our food, is made up of either elements or chemical compounds, some of which are beneficial and others not so (pp. 177-187). Antibiotics are a particular example discussed by Peter Silley, which may save lives if appropriately administered but, as they are also used to treat animals reared for meat, may end up in the food chain for humans and have deleterious on the microbial gut flora (pp. 189-194).

4. Occurrence of Aflatoxin M1 in milk in Iran: Alireza Khosravi and associates showed that the high variation in the concentration of aflatoxin $M_{1}$ in milk in Iran was dependent on the season and that over a third of more than 2,000 samples exceeded the European Union limit of $50 \mathrm{ng} \cdot \mathrm{l}^{-1}$. The variation is likely to be a reflection of differences in the seasonal contamination of the cows' feed with aflatoxin $B_{1}$ (pp. 533-539).

5. Contamination of broiler chicken feed with mycotoxins in Brazil: Carolina Rossi and co-workers found that $94 \%$ and $72 \%$ of broiler chicken feed in the northern part of 
Paraná State, Brazil was contaminated by fumonosin mycotoxins and aflatoxin, respectively. Although concentrations of the mycotoxins were low, rigorous monitoring of chicken feed is recommended in order to minimise the risk of mycotoxins entering the human food chain (pp. 541-550).

\section{Nutrition and food security}

1. Household food security in Timor-Leste: Marcelino da Costa and associates show how the inhabitants of TimorLeste cope with the 'hungry season' prior to the maize and rice harvest by diversifying their diet, with tubers playing a major role (pp. 83-94).

2. Wild vegetables as an important source of food in South Africa: Sydney Mavengahama and associates point out that wild vegetables not only improve the palatability of maize, the main staple, but are also an important source of micronutrients for combatting "hidden hunger", such as beta-carotene, zinc and iron (pp. 227-223).

3. Food security in rural areas of Limpopo province, South Africa: Fifty-three percent of people living in the rural areas of this province of South Africa said that they were severely food insecure, although the country does not have a generally accepted method of measuring food security. Human capital, income and location were the main determinants of food security status and these results indicated that promotion of rural education and creating a favourable environment for the rural labour market should be priorities in the future (pp. 269-282).

4. Rethinking the measurement of Food Security: This outstanding paper by Derek Headey and Olivier Ecker investigates four types of indicators for measuring food security; calories, poverty, dietary diversity and subjective indicators. The authors came to the overall conclusion that dietary diversity indicators were the best as they are powerful predictors of economic status and malnutrition, sensitive to shocks and relatively easy to measure (pp. 327-343).

5. Historical trends in food self-sufficiency in Africa: Yibo Luan and co-workers show that food self-sufficiency on the African continent declined precipitously from the 1960 s to the mid 1980s and at a slower rate up to the present time, probably as a result of increased population (pp. 393-405).

6. Food insecurity and coping strategies in South-West Nigeria: Dare Akerele and associates, using calorie consumption as their metric, found that food insecurity was widespread but of low severity. Because of high earnings from the oil industry, Nigeria imports over $\$ 3$ billion's worth of food annually rather than developing its own agriculture (pp. 407-414).
7. Securing food availability and affordability in Tanzania: Ruth Haug and Joseph Hella underscore the poor quality of roads and the cost of transport as factors that are likely to prevent Tanzania from attaining the first of the UN Millennium Development Goals viz. Eradication of Extreme Hunger and Poverty by 2015 (pp. 415-426).

8. Price transmission in local rice markets in Benin and Mali: Rose Fiamhoe and associates, found that the high transaction costs in Benin were associated with the long distance and bad state of the road, linking the surplus market to the consumption market. They suggest that investment in public infrastructure, such as roads, would promote the vertical integration of local rice production with marketing and thus improve rice farmers' food security and wellbeing (pp. 427-438).

9. Disaggregation of data in order to develop a sound food security policy: Muhammad Bashir and Steven Schilizzi found that food security of different household categories and micro-regions in Punjab province in Pakistan varied widely. They suggest that a "one size fits all" approach is inappropriate and policies should be adjusted to take into account regional and household differences (pp. 551-563).

10. The effect of farm level corruption on the food security of households in Bangladesh: Asif Anik and associates point out that corruption is usually reported at the macro level but this obscures its differential effect on households differing in expenditure levels. They found that low expenditure households were worst affected and that here corruption could force compromise of the food budget (pp. 565-574).

11. Choice of rice varieties in the food markets of Benin: Anwar Naseem and co-authors found that consumers were willing to pay a premium for rice with good physical qualities and imported rice despite the local production of high quality NERICA (new rice for Africa) varieties. The competitiveness of domestic rice relative to imported rice therefore needs to be increased (pp. 575-589).

12. Willingness of urban consumers to pay a premium for African leafy vegetables: Traditional African leafy vegetables (ALV) can be a valuable contribution to diet, particularly in respect of iron and vitamin A, but they have been neglected in plans to strengthen the agricultural sector. In Eldoret Town, Kenya, Philemon Chelang'a and co-authors found that consumers preferred ALVs to exotic leafy vegetables and were willing to pay prices approaching double for them (pp. 591-595).

13. Food, agriculture and US-Haiti relations: Marc Cohen points out the disconnect between US agricultural assistance to Haiti and its trade policy with the country. Although Haitians prefer local rice, they buy US rice 
because it is cheaper owing to trade liberalization, resulting in Haiti being the second largest market for US rice exports (pp. 597-606).

14. Agriculture and household nutrition security: John McDermott and associates emphasize the need for diet diversification through the production of nutritious and biofortified foods and stress the importance of enhancing the safety and quality of food. They also put these topics into a broader context which include four "next steps": aligning agricultural interventions with health, water, sanitation and social protection; enabling development through accelerated learning; building local and national capacity to adapt and innovate; and empowering (pp. 667-678).

15. Entry points into a nutrition-sensitive agriculture: Detlef Virchow and Hannah Jaenicke write that under-, maland over-nutrition are important and increasing global problems. Part of the reason is that the struggle against hunger has been mainly premised on increasing yields and nutritional quality has been disregarded. They advocate several ways to address this problem, including the use of traditional or underutilized crop (pp. 679-692).

16. Plant breeding for nutrition-sensitive agriculture: Anja Christinck and Eva Weltzien highlight the importance of broadening breeding programs towards people and their needs, especially those of vulnerable groups (pp. 693-707).

17. Gender, nutrition- and climate-smart food production: opportunities and trade-offs: Tina Beuchelt and Lone Bastue point out that, although conservation agriculture may have potential with regard to nutrition and being climate-smart, it may have undesirable effects for smallholders from gender and human development perspectives (pp. 709-721).

18. Nutrition sensitive urban agriculture: Maria GersterBentaya highlights the role and importance of urban agricultural production for a nutritious, diversified and therefore healthy diet, especially for the poor in urban societies, and fosters the idea of nutrition sensitive urban agriculture (pp. 723-737).

19. Production and processing of foods as core aspects of nutrition-sensitive agriculture and sustainable diets:
Gudrun Keding and associates point out that the achievement of nutrition-sensitive agriculture will require a trans-disciplinary approach, which will include the three sectors, agriculture, nutrition and health at research, extension and political levels as well as educated consumers who understand what constitutes a healthy and sustainable diet (pp. 825-846).

20. Home and community gardens in Southeast Asia: potential opportunities for contributing to nutritionsensitive food systems: Katinka Weinberger describes the potential for home and community gardens to contribute to nutrition-sensitive food systems in Southeast Asia, an area which is characterized by high levels of economic growth but also by unsustainable production and consumption patterns. Production from these gardens is almost exclusively for own consumption and has the potential to provide more nutritious food and healthier urban environments and lifestyles (pp. 847-856).

21. Nutrition-sensitive agriculture - a South African perspective: Milla McLachlan and Anri Landman assert that many South African households are not able to afford a balanced food basket at current food prices and income levels. This serious problem requires attention on several fronts. Entry points for nutrient-sensitive agriculture include linking small-scale production and nutrition education; strengthening alternative marketing channels and local food economies; monitoring food prices; and development of appropriate governance and institutional arrangements (pp. 857-871).

22. Leveraging agriculture to improve nutrition in the Philippines: Oscar Zamora and associates describe a number of successes of nutrition-sensitive agriculture programmes in the Philippines, including one with the acronym LAKASS, which has reduced the incidence of underweight, stunting and wasting in the most nutritionally depressed municipalities of the country. Other successes have included school-based production programmes, bio-intensive gardening and cropbreeding initiatives with sweet potatoes, maize and rice. The authors emphasize that, among other factors, the successes of these programmes were attributable to strong political will (pp. 873-886). 